\title{
Possible Experimental Mistakes in Agricultural Research
}

\author{
Ladislav Bláha \\ Crop Research Institute, Prague, Czech Republic \\ Email: opidum@volny.cz
}

How to cite this paper: Bláha, L. (2019) Possible Experimental Mistakes in Agricultural Research. Agricultural Sciences, 10, 1423-1437.

https://doi.org/10.4236/as.2019.1011104

Received: October 16, 2019

Accepted: November 15, 2019

Published: November 18, 2019

Copyright $\odot 2019$ by author(s) and Scientific Research Publishing Inc. This work is licensed under the Creative Commons Attribution International License (CC BY 4.0).

http://creativecommons.org/licenses/by/4.0/

(c) (i) Open Access

\begin{abstract}
The basic question is whether our contemporary methods really describe exactly the "plant world" around us, experiments or if it is the result of the current "imperfect" level of pieces of knowledge. Frankly, experiments are often burdened with many errors in sampling, in the selection of experimental plants, at the simulation of environmental stress, in light composition and lighting methods, shortly by a lot of mistakes. Experimental conditions of individual authors in evaluating the same issue often differ-that is to say, results are difficult to compare. The artificial experimental environment should simulate selected average external conditions of a given crop. Very important is the identification of important growth phases and traits that are suitable for the evaluation of the main experimental task. Bad results and also conclusions of experiments can be by either ignorance of these facts or by incorrectly prepared experiments. Very important is also a knowledge level of concerning tested problematic. The main goal is not only to point out the need for measuring important properties of plants in a physiologically correct stage of growth and development, by suitable methods but also on the influence of the properties of utilized seeds in experiments that they can modify plant growth and development. It is often forgotten that impact of stress on the seeds' properties and through the seed traits on the plant properties, for example, the same variety in of different provenance may give different results, especially influence on the roots, because plant roots are the most sensitive part of plants. Only the different origins of used seeds in identical experiments at two workplaces can significantly change the results of every repeated standard experiment.
\end{abstract}

\section{Keywords}

Agricultural Experiments, Errors, Possible Causes 


\section{Introduction}

Agricultural experimentation is over 173 years old. In 1840, J. Blawes, the owner of the firm in Rothamsted in the south of England, began to carry out pot experiments, and in 1843 he converted the farm with J. Gilbert into a model test station.

In the 20th century begin development of the agricultural research institutes, the gradual development of experimental methods made considerable progress. At the present time, gradual shift exists in the role of experiments to the connection between science and practice by various forms of communication. More detailed information can be found in [1].

\section{Material (Sources of Information)}

To tell the truth, experimentation is a basic component of almost every biological, agricultural and another scientific endeavor. Properly designed experiments answer on most questions of the researcher. Thus, efficient designing of an experiment is a very important activity. It is a common phenomenon that the research problems are defined clearly but often do not use appropriate methods for analysis.

There are a number of sources of variation in field experiments, and these sources all can contribute to the emergence of experimental error.

Usually, a new issue that originated should use a new methodology.

Important information concerning experimental methods is available in the following publications [2]-[8]. But from time to time the question is the practical conduct of the experiments.

\subsection{The Knowledge of Plant Integrity Is Neglected Thank to the "Narrow" Specialization of Researchers}

Plant integrity is very important, to understand to the obtained experimental results, because plants represent an integrated system of units, which are responsible for its resistance to adverse environmental conditions, on the basis of the evaluation of characteristics both aboveground and in the roots.

Evaluation of plants and stands in the wrong phase of growth and development at unsuitable traits can cause experiment bias of results.

The "complete unit" (root and shoot) has an influence on the formation of seeds, the quality of which may affect subsequent growth, development, and stress tolerance of the filial generation.

Most stressors always have a pleiotropic effect on the plant, on the activity of a number of genes and the content of various substances (ABA, heat shock proteins, free radicals), change in osmoregulation, etc.

Properties of the roots predominantly influence growth, development, and the metabolic processes in the aboveground part of the plant. The seed traits affect the filial generation root morphology at the beginning of the vegetation period. Every plant, and its traits is a result of all the plant's activities. This is important for founding type of tests, organisation of test and selecting analysed characters. 
For example of the importance of complex analysis here is example of tumors on spruce (Figure 1, Picea sp.) and poplar (Figure 2, Populus sp.), which is already bark-free.

We can read in various articles, a lot of information about the cause of cancer, but without complex analysis, i.e. without proper biochemical analysis, DNA analysis, anatomic wood tissue analysis, histological and cytological analysis, activities of the root system etc. we cannot obtain the truth.

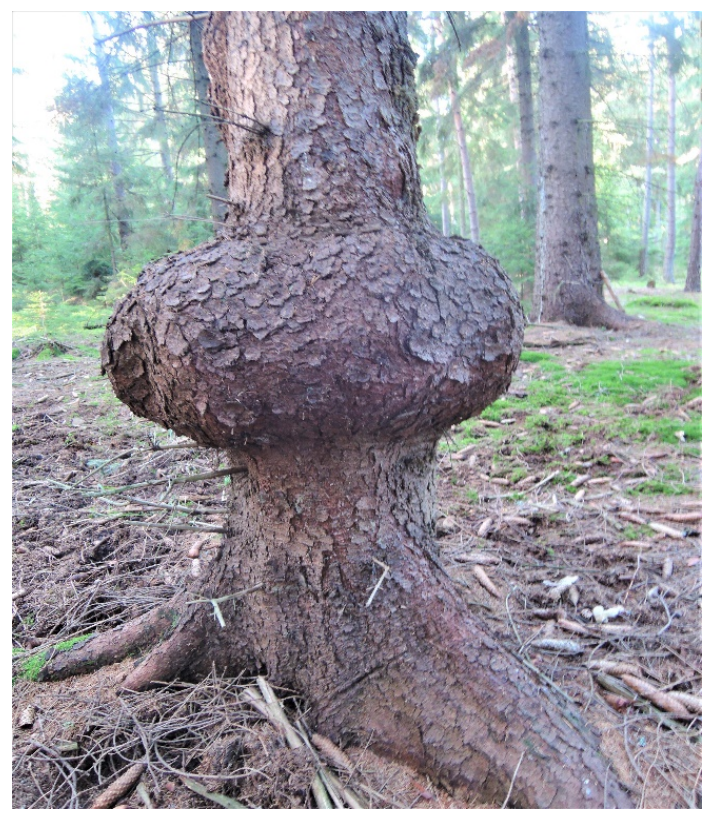

Figure 1. Tumor of Picea sp.

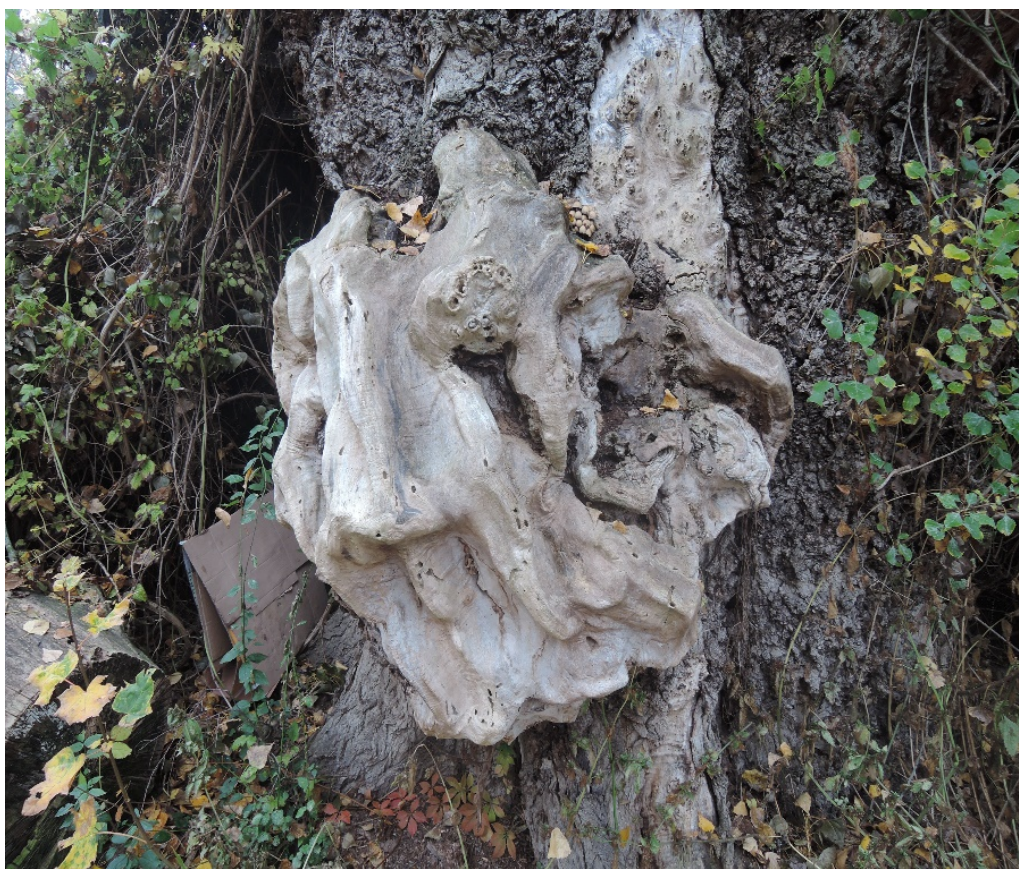

Figure 2. Tumor of poplar sp. 


\subsection{Establishing of Optimal Experiment Conditions}

Evaluation of plants and stands in the wrong growth and development phase can cause experiment bias of results.

When we read scientific publications, at first glance it acts as a good articles, and can be said to be a top-class work, the way of processing the results is excellent, but the measured plant parameters do not really correspond to the actual condition of the plant from nature (field) and often vary between workplaces, between greenhouse results, used climatic chambres. It is also desirable to adjust the cultivation conditions as much as possible so that the plants are as close as possible to the natural average conditions in nature.

The magnitude of experimental error attaching to one or more field plots is of importance in Agricultural Science, [9]. Yield (or other traits) values from crops recurring on the same plots in long-term experiments are subject to correlations known as serial plot correlations. Neglect of these plot correlations can result in loss of efficiency in the estimation of experimental treatment effects and bias in the estimation of error [10] [11].

\subsection{The Most Common Experimental Errors That Can Be Observed}

In the following text are the results of official and individual discussions at 10 conferences (ESA) - mainly from workshops. The results of the discussions can be summarized in the following categories. For many reasons, it is not possible to cite works denoting the described errors (especially for legal reasons).In order to understand the metabolism of plants in the evaluation of this issue-i.e. experimental mistakes, the references for this text include also at the end a group of citations clarifying the metabolism in this respect. [see: supplementary references].

\subsubsection{Experiments Simulating Salinity}

In a group of salinity trials, this stressor is predominantly simulated during vegetation. Then it is simulated what is not in nature, in the salinas environment is already at the beginning of seed germination. This is also often the case with heavy metal experiments, i.e. late application and then draw conclusions from something that practically does not exist in nature.

However, a specific problem is the secondary salinization of the container experiments. In some cases, as follows form experimental methods, long-term experiments in a greenhouse are watered with tap water, which contains: chlorides, magnesium, nitrates, trihalomethanes, especially chloroform, bromoform, dibromochloromethane, and bromodichloromethane. The concentration of salts in water is often relatively high. Secondary salinization occurs.

\subsubsection{Size of Experimental Pots}

In small experimental pots, the natural roots: above-ground part ratio is different, with a certain probability there may also be larger fluctuations in soil mois- 
ture. In a longer experiment, nutrient depletion results if nutrients are not continuously supplied. Also, the higher temperature fluctuation in the root system is likely. Higher temperatures cause increased respiration of the roots.

If the test plants of a given crop variety deviate by their natural parameters from those normally grown in field conditions, then in most cases results do not constitute an objective evaluation of the plant (a cultivar of a crop). It is preferable to use climatic chambres where the containers are set into the second low box with cooling. In this case, there are more possible technic solutions.

The problem may also be enlarged by the continuous removal of plants from containers in some types of experiments. If plants are withdrawn gradually from the test vessel, the remaining plants grow further in a different environment.

\subsubsection{Cultivation Media in Experiment Containers (Pots)}

The culture medium strongly modifies the properties of the root system due to the sensitivity of the roots to the external environment and subsequently the above-ground part. The root system modifies the pot size, temperature, watering, nutrition, microflora, etc. Very often it exists a strong positive correlation between the growth of the above-ground part of the plant and the volume of the cultivation vessel.

As the size of the container increases, the importance of its size decreases and the roots are approaching the natural environment. The size of the container must approximately match the requirements of the cultivated species.

In general, per liter of dry matter of the biomass of a plant should be 1 liter of container volume.

It can be assumed that about $60 \%$ - $70 \%$ of experiments have a volume of containers unsatisfactory.

In addition, it is quite a deterrent if an experimenter evaluates, for example, wheat in a horticultural humous substrate and the other has a similar experiment in classical soil.

\subsubsection{Hydroponics}

It can be stated that there are persistent mistakes. In the case of lower aeration intensity, this method of cultivation can act de facto as anoxia. Then, in this case, if the results of hydroponics and simulated anoxia on the same crop come together, they do not differ in the measured metabolic parameters... However, it depends on the crop.

It is also advisable to regularly replenish nutrients or change the solution during long-term cultivation. A slightly different situation arises if hydroponics has the continuous mixing of solutions during growth and a large volume of solution exists, then can be used lower levels of nutrients (up to 100 times lower due to flow, but not everyone sciencist agree).

Changing the nutrient content as well as the activity of the roots affects the $\mathrm{pH}$ change of the solution. If the solution does not change in long-term experiments, care should be taken to adjust the $\mathrm{pH}$ factor. This is not always common 
in published experiments.

If more light penetrates the nutrient solution, which is not even suitable for the root system, we may encounter algae and fungi that take nutrients and oxygen. Root diseases may also occur. The most common root disease in hydroponic systems is caused by fungi of the genus Pythium. Other fungal diseases that occasionally cause problems include, for example, Fusarium sp., Phytophthora sp. and Rhizoctonia sp.

If the optimum temperature for the root system of $15^{\circ} \mathrm{C}-27^{\circ} \mathrm{C}$ for individual species is not maintained, i.e. always lower than the temperature of the above-ground part of plants (on average it is lower by $10^{\circ} \mathrm{C}-15^{\circ} \mathrm{C}$ ), the plants differ from habitats from natural habitats.

\subsubsection{Plant Growing in a Decreasing Length on Day}

Repetition of experiments with spring crops, i.e. with the cereals, grasses, spring rape etc. i.e. during the second half of vegetation period-near the autumn, is with the problem of changing the intensity of light, spectrum and shortening of day length. Then there is the possibility to obtain different results at analyzed crops. Therefore it is necessary to pay attention to artificial lighting, in greenhouses so that the spectrum is similar throughout the year.

\subsubsection{Unsuitable Temperature Mode for the Root Environment}

An inappropriate temperature of the root culture medium affects growth and development and ultimately the plant morphology, yield, and elements. In nature, with the exception of the soil surface, the temperature of the root system during vegetation is lower than in the above-ground part.

The temperature regime of the roots affects the content of cytokinins, auxin, intake of nutrients, nitrogen metabolism, health, and respiratory intensity. In nature, in the summertime, plants have a significant difference between the air temperature and the root rhizosphere (not at the soil surface!) This difference is about $10^{\circ} \mathrm{C}-15^{\circ} \mathrm{C}$ and is optimal for growth and development.

The high temperature in the root zone decreases the growth of the leaves and the performance of the above-ground part of the plants due to the increased intensity of respiration of the roots and decrease the intensity of photosynthesis, especially in C4 plants.

Especially the higher temperature in the greenhouse with pot experiments at night also causes a higher temperature of the root system in the pots, resulting in less plant habitus, leaf and stem weight. Plants grow most at night from assimilates formed during the day.

\subsubsection{Greenhouses and Climatic Chambres}

\section{1) Greenhouses}

The following conclusions can be traced from publications, poster presentations and discussions at conferences:

- Small test vessels (already mentioned): the result is poor root development, 
rapid drying of soil if automatic irrigation is not in place, nutrient depletion is frequent unless supplementation is ensured,

- The luminaires are often only statically placed at one height, the higher the plants, the more uneven is the lighting, moreover, unsuitable luminaires (intensity and spectrum) are often used.

- Humidity and $\mathrm{CO}_{2}$ content are not controlled

- Mixing of air is not introduced, this artificial flow is very advantageous!!

- The temperature of the medium in which the roots grow is close to the air temperature, which is not a natural phenomenon,

- There isn't often automatic watering according to soil sensor.

Note: It is important to highlight that from time to time plant traits are measured at a different stage of growth and development than needed, because it is the evaluation of plants according to calendar terms in some cases and not according to the growth and development phase.

\section{2) Climatic Chambres}

- Similar conclusions as in the greenhouse are obtained and moreover is possible to state:

- The lack of air exchange

- Small boxes often suffer from increased levels of $\mathrm{CO}_{2}$, not because of the physiological activity of plants, but mainly thank soil production if they contain more humus. The results of the experiments are distorted due to the increased concentration of carbon dioxide and other gases during vegetation.

- Often lack of air is mixing,

- No control of air composition and humidity exists.

- Type of lighting - is not suitable, i.e.-the intensity of light and its composition.

\subsubsection{Sowing Experiments in the Soil That Has Been Long Term Stored} Most experimenters use the appropriate soil for the crop in pot experiments. However, soils that have been stored in large quantities for a long time and dried up, can affect the results due to very slow recovery of microbial activity at the beginning of vegetation, especially mycorrhiza, which is virtually part of life in $80 \%$ of plant species and moreover, they provide some of their products to the plant, affecting its metabolism. In short-term experiments, we can influence the measured physiological parameters of plants. If unsuitable, atypical or dried culture substrates are used, the plant always has a different metabolism especially at begin of growth.

\subsubsection{Problems of Statistical Methods in Agriculture and Experimental Biology}

Researchers often do not pay enough attention to correct statistical analysis applications in all stages of the investigation.

Practically speaking, there are errors in setting up experiments, sowing, harvesting, measuring, and processing results, in the statistical evaluation and in in- 
terpreting results.

Frequent phenomena are inaccurate experiments both in the field, greenhouses and in laboratory conditions, and vice versa the mathematical criteria used are very strict

It is a human systemic error (accurate analysis with inaccurate numbers)

The minimum number of plants per repetition and the minimum number of repetitions is a crucial frequent mistake. The number of genotypes evaluated must correspond to the requirements of the experiment.

(In the case of breeding, the situation is more complicated, as the number of plants in each generation Fn is different).

Which are a basic important question of statistical analysis-important for a good solution to the problem? These are mainly these topics in the following overview:

- Are the experimental areas typical?

- How are plants treated?

- How are they grown?

- How many repetitions are required?

- Ecological procedures are applied in such a way that the experiment gives meaningful results?

- Do the traits characterize the-pursued goal?

- What is the required scope of the results?

- Are the framework conditions constant (pre-crop, treatment, harvest time)

- Is the size of the test plot optimal? The seeding direction is arranged so that the known variability between the blocks is maximized and the variation in the blocks is minimized? Is the edge effect eliminated?

- Are single-factor experiments, multi-factor experiments differentiated?

- Is appropriate statistical analysis used to test the hypothesis?

- Correlation is often used as a characteristic implying a cause. It must be said, it is not always! Sometimes it relies only on a statistical test to evaluate an experiment. If there are type of conclusions "we have accepted/rejected at a certain \% level of significance tested hypothesis", then it is a work where the significance of the information content of a statistical test was not understood.

The statistical test says something else, does not confirm or even refute the (mostly) hypothesis. For example, if there is a change of significance level, the conclusions would then be different. The basis must be the biological nature of the test.

Another example may be the long-term effect with a relatively small difference in the size of the germinal roots, but which in turn affects the entire vegetation. Statistically non-significant differences at these traits exist, but operating during all vegetation period. Often the differences in embryonic root size are only at a $10 \%-25 \%$ significance level, but measurable effect on the yield differences at $1 \%$ or $5 \%$ significance level is due to the effect of this phenomenon which usually lasts the entire vegetation. 


\subsubsection{The Lower Seed Quality}

The variety and provenance of the seed can influence not only the parameters of the germinating plants but also the whole subsequent course of vegetation, thus also in the eventually evaluated physiological properties of the plants.

Identical experiments at two workplaces in joint project can be distorted due to the fact that even though the same variety is used, different provenance is used at each workstation.

For the establishment of field and especially accurate laboratory experiments, the key parameter is also the varietal purity of the seed patterns.

The use of protein genetic markers based on electrophoretic methods is a useful tool for evaluating the quality and equilibrium of the seed used, especially for cereals in the evaluation of admixture content, and can be focused on variety identification, differentiation between different varieties and last but not least on varietal purity control

\subsubsection{Stress during Seed Storage May Affect the Properties of Seeds and Plants Grown from the Seeds}

If the seed has lower germination energy due to storage conditions, then the growth of plants in the experiment from this seeds is slowed, but generative development is running and result is a lower yield.

\section{Additional note}

Stress during storage also affects not only seed quality but also seed life. It is genetically conditioned. Some seeds survive for several weeks, and the opposite are seeds surviving 15 - 20 years (even several thousand years-seeds that survived in permafrost $\ldots$ )

In addition to the changes in the content of basic substances, the manifestation of the aging of seeds is minor morphological changes, ultrastructural changes of cells, loss of enzyme activity during germination, respiration reduction, fatty acid growth, ribosome malfunction, hydrolytic enzymes, growth of phenolic substances, growth of somatic mutations, accumulation of polyphenolic substances, reduction of oxygen supply of the embryo, etc.

\subsubsection{In Lot of Scientific Work, the General Conclusion Is Derived Only from Two Contrasting Varieties}

For example, in the case of dry resistance the tested property can be achieved, in various ways-by different levels of metabolism (good solution), or just because one of the varieties is very early variety, escapes during the vegetation to the dry season but the metabolism both of cultivars is similar (bad solution), then it is difficult to compare results...

\subsubsection{Errors Caused by Uncontrollable Influences}

This is in this case errors uncontrollable by the experimenter as a higher ozone concentration, flue gas concentration in the air, irrigation water pollution, poor color in greenhouse or box releasing toxic products, elektricity failure, hail, human error, meteorite crash, earthquake, flood, death, etc. 


\section{Conclusions}

The basic aim is an attempt to point out some mistakes of experimental techniques. The presented information is obtained from the literature, and from the discussions and workshops at various conferences, where were discussed reasons for quite different experimental conclusions from some laboratories with similar experiments.

Only the information where there was a consensus of more workers is given.

This is very important, particularly in the case of the same basic experimental aim, in case of the same utilized experimental material in the analysis of the same stages of growth and development, but presented results are different.

As already described in other publications, the current system of accepting new varieties in many European countries is not in the direction of variety plasticity, but rather in the morphological homogeneity of the genetic material. It isn't suitable situation.

Plastic varieties return to the state of their original metabolism during the vegetation period after the stress has ended.

It is therefore also important what varieties to use in the experiments. It can be assumed that it will be easier to measure varieties that are varieties intended only for specific conditions (drought, low $\mathrm{pH}$, salinity, poor soils).

\section{Additional Notes}

It is assumed that the application of digital image processing can open new possibilities in the evaluation of agricultural experiments. With the help of images about plants we can measure them in their natural environment without mutilation, respectively sampling. Image processing can be used for example for the identification of various fungi and wit different other algorithms making shape recognition possible. Image processing systems make the evaluation of indistinguishable changes possible. By determining intensity values the scale of changes will be numerical and later on they can be evaluated by the traditional mathematical statistical methods. In order to discover the reasons of changes or to stop the causes it can be important to examine their dynamics on one plant [12].

To tell truth in many cases the consequences and not of the phenomenon are analyzed.

There are many works in the literature to evaluate the structure of the wheat ear, i.e. the number of spikes, spikelets, flowers. The area of flag leaves is analyzed, the value of the harvest index and the correlation of these characteristics with yield elements are calculated. In conclusion, there is a recommendation on how to provide selection on the basis of the harvest, index, etc. The correlation analysis is calculated and the elements important for the yield are determined. Due to the correlation analysis, the causes and consequences are derived here.

But the essence of the phenomenon at semidwarf wheat cultivars is that a number of obtained correlations are due only to a change in the ratio of roots to the aerial part. 
Often root development is in advance over the aerial part, changes in photosynthesis intensity due to better light penetration into the lower parts of plants exist, transport in the plant is improved because of the roots reach their maximum development earlier than shoots.

The basis is therefore not only in the type of experiment, using statistical analysis, but also in the level of pieces of knowledge concerning the whole plant physiology.

\section{Conflicts of Interest}

The author declares no conflicts of interest regarding the publication of this paper.

\section{References}

[1] Maat, H. (2011) The History and Future of Agricultural Experiments. NJASWageningen Journal of Life Sciences, 57, 187-195. https://doi.org/10.1016/j.njas.2010.11.001

[2] Montgomery, D.C. (2017) Design and Analysis of Experiments Arisona, State University. Ninth Edition, John Wiley \& Sons, New York, 640 p.

[3] Petersen, G. (1994) Agricultural Field Experiments: Design and Analysis. In: Books in Soils, Plants, and the Environment, CRC Press, London, $426 \mathrm{p}$.

[4] Rasmussen, P.E., Goulding, K.W.T., Brown, J.R., Grace, P.R., Janzen, H.H. and Martin Körschens, M. (1998) Long-Term Agroecosystem Experiments: Assessing Agricultural Sustainability and Global Change. Science, 282, 893-896. https://doi.org/10.1126/science.282.5390.893

[5] Petersen, R.G. (1985) Design and Analysis of Experiments. Monticello, New York.

[6] Mead, R. (2017) Statistical Methods in Agriculture and Experimental Biology. CRC Press, Boca Raton, FL. https://www.bookdepository.com/Statistical-Methods-Agriculture-Experimental-Bi ology-Roger-Mead/9781584881872

[7] Neyman, J., Iwaszkiewicz, K. and Kolodziejczyk, S. (1935) Statistical Problems in Agricultural Experimentation. Supplement to the Journal of the Royal Statistical Society, 2, 107-180. https://www.jstor.org/stable/2983637 https://doi.org/10.2307/2983637

[8] Steponas, R. (2017) Application of Statistics in Plant and Crop Research: Important Issues. Zemdirbyste-Agriculture, 104, 377-382. https://doi.org/10.13080/z-a.2017.104.048

[9] Loughin, T.M., Cox, D.F., Hinz, S.N., William, T.J. and Kilgore-Norquest, L. (1994) Experimental Error in Agronomic Field Trials. 1994 6th Annual Conference Proceedings of Applied Statistics in Agriculture. https://doi.org/10.4148/2475-7772.1356

[10] Patterson, H. and Lowe, B. (1970) The Errors of Long-Term Experiments. The Journal of Agricultural Science, 74, 53-60. https://doi.org/10.1017/S0021859600020943

[11] Mercer, W.B. and Hall, A.D. (2009) The Experimental Error of Field Trials. The Journal of Agricultural Science, 4, 107-132.

https://doi.org/10.1017/S002185960000160X 
[12] Berke, A.S.J., Győrffy, K., Fischl, G., Kárpáti, L. and Bakonyi, J. (1993) The Application of Digital Image Processing in the Evaluation of Agricultural Experiments. In: Chetverikov, D. and Kropatsch, W.G., Eds., Computer Analysis of Images and Patterns, Lecture Notes in Computer Science, Springer, Berlin, Heidelberg. https://doi.org/10.1007/3-540-57233-3_108 


\section{Suplementary Reference}

(Supplementary non-cited literature, related to experimental errors, explaining the described crops physiology, paragraph 2.3 page 2)

Achim W., Silk W.K., Schurr U. 2009: Environmental Effects on Spatial and Temporal Patterns of Leaf and Root Growth. Annu. Rev. Plant Biol., 60: 279-304.

Anderson J.E., McNaughton S.J. 1973: Effect of low soil temperature on transpiration, photosynthesis, leaf relative content and growth among elevationally diverse plant populations. Ecology, 54: 6.

Atkin O.K., Loveys B.R., Atkinson L.J., Pons T.L. 2006: Phenotypic plasticity and growth temperature: understanding interspecific variability. Journal of EXperimental Botany, 57: 267-281.

Baluška F., Mancuso S. 2009:Plant-Environment Interactions. Springer Verlag: Berlin.

Baluška F. 2009: Plant Signaling. Springer Verlag: Berlin.

Baluška F., Volkmann D., Mancuso S. 2006: Communication in Plants: Neuronal Aspects of Plant Life. Springer Verlag: Berlin.

Behboudian M.H., Graves W.R., Walsh C.S.,Koreak R.F. 1994: Water relations, mineral nutrition, growth, and $13 \mathrm{C}$ discrimination in two apple cultivars under daily episodes of high root-medium temperature. Plant and Soil, 162: 125-133.

Berry W.L., Knight S. 1997: Plant culture in hydroponics. In: Langhans R.W., Tibbitts T.W. (eds), Plant growth chamber handbook, Iowa State University: Ames, IA, pp. 119-131.

Bite A., Lepsis J. 2004: The results of extended duration testing of apple rootstocks in Latvia. Acta Hort., 658: 115-118.

Bláha L., Hnilicka F., Hořejší P., Novák V. 2003: Influence of abiotic stresses on the yield, seed and root traits at winter wheat (Tritium aestivum L.). Scientia Agriculturae Bohemica, 34(1): 1-7.

Bláha L., Klíma M.,Vyvadilová M. 2011: The infleuence of the seed traits on the yield of selected genotypes of winter trape. In: Nové poznatky z genetiky a šlacht̉enija polnohosspodárských rastlín, Pieštany, pp. 69-72.

Bláha L., Gottwaldová P. 2008: Changes of the seed germination during the year. $10^{\text {th }}$ Congress of the European Society of Agronomy, 15-19 September, Bologna, Italy, 387-388.

Bláha L., Šerá B. (eds)2013: Importance of plant integrity in research, breeding and production. VÚRV, Praha, ISBN 978-80-9044351-6-2.

Brown W.W., Ormrod D.P. 1980: Soil temperature effects on greenhouse roses in relation to air temperature and nutrition. J. Amer. Soc. Hort. Sci., 105(1): 57-59.

Cooper A. 1976: Nutrient film technique of growing crops. Grower Books: London. 
Cooper A.J. 1973: Root temperature and plant growth. Commonwealth Agricultural. Bureaux, Slough, England.

Davies W.J., Van Volkenburgh E. 1983: The influence of water deficit on the factors controling the daily pattern of growth of Phaseolus trifoliates. J. Exp. Bot., 34: 987-9935.

Engels C. 1994: Effect of root and shoot meristem temperature on shoot to root dry matter partitioning and the internal concentrations of nitrogen and carbohydrates in maize and wheat. Ann. Bot., 72, 311-19.

Fitter A.H., Hay R.K.M. 2002: Environmental physiology of plants. Academic Press: London.

Ganmore-Neumann R., Kafafi U. 1985: The effect of root temperature and nitrate/ammonium ratio on strawberry plants. Agron. J., 77: 835-840.

Geather A.Ch., GAIL R., Graves W.R., Aiellol A.S., Dilley C.A. 1997: High RootZone Temperatures Inhibit Growth and Development of Fragaria Species Fruit. Varieties Journal, 51(2): 94-101.

Gosselin A., Trudel M. 1983: Interactions between air and root temperatures in greenhouse tomatoes:

Heins R.D., Wilkin H 1979:. Effect of soil temperature and photoperiod on vegetative and reproductive growth of Alstroemeria 'Regina'. J. Amer. Soc. Hort. Sci., 104: 359-365.

Hewitt E.J. 1966: Sand and water culture methods used in the study of plant nutrition. Technical Communication no. 22. Commonwealth Bureau of Horticulture and Plantation Crops, Great Britain.

Chen Y., Katan J. 1980: Effects of solar heating of soils by transparent polyethylene mulching on their chemical properties. Soil Sci., 130: 271-277.

Chermnykh L.N., Kosobrukhov A.A. 1987: Effect of environmental factors on optimum temperature and photosynthetic intensity of plants adapted to various conditions. Biotronics, 16: 1-11.

Janes H.W., McAvoy R. 1982: Effect of root zone heating on growth of poinsettia. J. Amer. Soc. Hort. Sci., 107: 525-530.

Jones D.A.G., Sandwell I., Talent C.J.W. 1978: The effect of soil temperature when associated with low air temperatures on cropping of early tomatoes. Acta Hortic., 76 : 167-171.

Karlsen P. 1997: Root temperature and stem elongation. In: K.E. Cockshull, F.A. Langton, P,J. Lumsden (eds), Proc. Second Workshop Env. Reg. Of Plant Morphogenesis, Acta Hort. 435, ISHS.

Keeling C.D., Chin J.F.S., Whorf T.P. 1996: Increased activity of northern vegetation inferred from atmospheric $\mathrm{CO}_{2}$ measurements. Nature, 382: 146-149.

Keil-Gunderson L.S., Goldsberry K.L., Chapman P.L. 1989: Air and substrate temperatures for 'Atlas' and 'Monika' Alstroemeria. Hort Science, 24: 613-616.

Kosobruskhov A. A., Velichkov D., Stanev V. 1990: Effect of various temperatures in the root zone and light intensities on photosynthesis and transpiration of totmato plants. Biotronics, 19: 1-6. 
Lambers H., Pons T.L., Chapin F.S. 2008: Plant physiological ecology. Springer Verlag.

Langhans R.W., Tibbitts T.W. (eds) 1997: Plant growth chamber handbook. Iowa State University: Ames, IA.

Larcher W. 2003: Physiological plant ecology. Springer Verlag: Berlin.

Lecharny A., Schwall M., Wagner E. 1985: Stem extension rate in light-grown plants. Plant Physiol., 79: 625-629.

Leishman M.R. 2001: Does the seed size/number trade-off model determine plant community structure? An assessment of the model mechanisms and their generality. Oikos, 93: 294-302.

Lilley J.M., Fukai S. 1994: Effect of timing and severity of water deficit on four diverse rice cultivars. II. Physiological responses to soil water deficit. Field Crops Research, 37: 215-223.

Markhart A.H., Fiscus E.L., Naylor A.W., Kramer P.J. 1979: Effect of temperature on water and ion transport in soybean and broccoli systems. Plant Physiology, 64: 83-87.

Moorby J., Graves C.J. 1980: Root and air temperature effects on growth and yield of tomatoes and lettuce. Acta Hort., 98: 29-44.

Morison I.L., Morecrfoft M.E., Viner D., James I.L.,Wallace M.,Wallaced C. 2006: Recent and future climate change and thein implications for plant growth. In: Plant Growth and climate change, Blackwell publishing Ltd, pp. $1-17$.

Munns R. 2002: Comparative physiology of salt and water stress. Plant, Cell and Environment, 25: 239-250.

Poiré R., Schneider K., Michael R.R.M., Kuhn A.J., Schur U., Walter A. 2010: Root cooling strongly affects diel leaf growth dynamics, water and carbohydrate relations in Ricinus communis. Plant, Cell and Environment, 33: 408-417.

Remkes H.C., Lambers H. 1990: Carbon and nitrogen economy of 24 wild species differing in relative growth rate. Plant Physiology, 94: 621-627.

Sager J.C., McFarlane J.C. 1997: Radiation. In: Langhans R.W., Tibbitts T.W. (eds), Plant growth chamber handbook, pp. 1-29, Iowa State University: Ames, IA.

Smith H. (ed) 1984: Plants and the daylight spectrum. Academic Press: London.

Spomer L.A., Berry W.L., Tibbitts T.W. 1997: Plant culture in solid media. In: Langhans R.W., Tibbitts T.W. (eds), Plant growth chamber handbook, pp. 105-118, Iowa State University: Ames, IA.

Tagliavini M., Looney N.E. 1991: Response of/each seedlings to root-zone temperature an root-appliea growth regulators. HortScience, 26: 870-1172.

Thompson H.C., Langhans RF.W., Both A.J., Albright L.D. 1998: Shoot and Root Temperature Effects on Lettuce Growth in a Floating Hydroponic System. J. Amer. Soc. Hort. Sci., 123: 361-364.

Tibbitts T.W. 1997: Air contaminants. In: Toppi R.W., Skowroňska B.P. (eds), Plant growth chamber handbook. Abiotic stresses in Plants,Kluwer. 